\title{
Biology of mango inflorescence gall midges Desineura amaramanjarae recently found in Sindh, Pakistan
}

\section{Muhammad Qasim Memon ${ }^{1}$, Abdul Ghani Lanjar ${ }^{2}$, Muhammad Khan Lohar $^{3}$, Maqsood Anwer Rustamani², Abdul Sattar Buriro ${ }^{1}$, Muslim Qadir $^{4}$ and Shahzad Ali Nahiyoon ${ }^{3 *}$}

1. Entomology Section, Agriculture Research Institute, Tandojam-Pakistan

2. Department of Plant Protection, Sindh Agriculture University Tandojam-Pakistan

3. Department of Entomology, Sindh Agriculture University Tandojam-Pakistan

4. Oil Crop Research Institute of Chinese Academy of Agricultural Sciences, Wuhan 430063, Hubei-China

*Corresponding author's email: Shezi_129@yahoo.com

Citation

Muhammad Qasim Memon, Abdul Ghani Lanjar, Muhammad Khan Lohar, Maqsood Anwer Rustamani, Abdul Sattar Buriro, Muslim Qadir and Shahzad Ali Nahiyoon. Biology of mango inflorescence gall midges Desineura amaramanjarae recently found in Sindh, Pakistan. Pure and Applied Biology. Vol. 9, Issue 2, pp1304-1312. http://dx.doi.org/10.19045/bspab.2020.90135

Received: 11/11/2019 Revised: 21/01/2020

Accepted: 06/02/2020

Online First: 17/02/2020

\section{Abstract}

Gall midges are major pests in all mango cultivated areas of the globe. A complex of gall midge's damages mango in Pakistan. The Dasineura amaramanjarae Grover, 1965 (Diptera: Cecidomyiidae), one such midge pest that feeds on mango inflorescence, was first time recorded in Sindh during 2008. They damage many parts of the plant including the leaves, shoots, bark, pre and post-flowering shoot buds, inflorescence buds, axillaries, newly formed fruit and twigs. The biology of mango inflorescence Dasineura amaramanjarae, was studied. The results showed that the adult emerged between 8.00 am to 12.00 am and matting started soon after adult emergence, mostly recorded in the morning time. The female of Dasineura amaramanjarae lay their eggs (40-50) in 8-10 minutes' interval. After hatching, the young larvae start their feeding, destroy the flower buds and also make a small tunnel in branches. The infested buds had red-coloured petals, the flower buds become dark, dry and fall off. The inflorescence gall midges were recorded from January to June, the activity of midges was at the peak in the month of March and decreased up to June. After full feeding, mature larvae leave the inflorescences and enter to the soil for pupation. The mean percent of infested inflorescence was determined at $50.21 \%$ and $65.71 \%$ respectively. In natural conditions the development from egg to adult completed in 373.00-448.00 hours respectively. These results illustrated the biological plasticity of Dasineura amaramanjarae. Consequences of these results to elaborate IPM strategies against the mango inflorescence gall midges are discussed.

Keywords: Biology; Dasineura amaramanjarae ; Gall midges; Inflorescence; Mango; Pests; Sindh

Introduction

The mango cultivated in Indo-Pak subcontinent since 4000 years, is the most relished fruit in the world. Mango, Mangifera indica L. is grown in lowland tropical and sub-tropical areas throughout the world. Its cultivation expended due to the demands has been increased day by day. Pakistan stands 
fourth in the ranking of mango producing and exporting countries [1-3]. The production of mango is undermined by more than 250 insect pests in the world [4]. In Pakistan, about 200 species of insect pests attacking mango, have been reported $[5,6,7,8]$. Among these, about 20 species of gall midges are known worldwide related with different parts of mango plant including leaves, shoots, bark, inflorescence buds, pre and postflowering shoot buds, axillaries, flowers, newly formed fruit and twigs [9-12].

Dasineura amaramanjarae is one of the midge pests of mango which feeds on flower buds. Female lays eggs near the stamens, larvae feed inside the flower buds and fullgrown larvae drop to the soil for pupation. In the case of severe infestation, the reduction in yield can reach $60 \%$ to $100 \%[13,14]$. Grover reported that the adults emerge from the soil and immediately pair at the start of the flowering season $[15,16]$. A single female lays 40-50 eggs which are hatched in 30-36 hours, depending upon the temperature and humidity. There are four larval instars and the second and third instars cause the most of the damage. Prasad study that the pupation and diapause take place in soil under the mango tree [17]. Several larvae have been recorded from a single flower but there is only one larva was found per gall. The attacked panicles become dry and fall due to slight pressure of winds thus the loss of flower and newly set fruits occur. Prasad noted the infestation of the pest on mango fruits and reported that it is an important pest of mango that causes $60-100 \%$ fruit losses to mango production due to fall of hollowed fruits in the soil [14]. Prasad and Grover, reported the midge caused heavy fruit losses due to premature fall of mango without completing their development [13, 17]. The Grover estimated losses to $100 \%$ and all most all flowers are being damaged [18, 19]. Besides inflorescences, leaves are also damaged by midges indicating a complex species of midges. A list of midges in India was also provided [4]. However, no particular information on mango midges exists in Pakistan especially in Sindh [8]. Therefore, to achieve optimal outbreaks of this pest, it is necessary to understand the biology of mango inflorescence gall midges Dasineura amaramanjarae. The results of this study will provide useful information for integrated pest management programs.

\section{Materials and methods}

Survey of midges from different mango orchards

In order to determine the presence of Dasineura amaramanjarae, surveys of midges were carried out only on leaves and flowers of mango during the period 20072009. For this purpose, some orchards in Hyderabad, Tando Allahyar and Mirpurkhas Districts were surveyed at fortnightly intervals on the Nine Varieties (Early, Middle and Late). The orchards under observation were as under. Mir Munwar Farm Khwaja Stop Mirpurkhas, Mohammad Umar Bughio Near Mir Wah Raod Mirpurkhas, Mir Zamin Farm Hyderabad Road, Hyderabad, Horticulture Farm Mirpurkhas, Dehli Farm Tandojam Hyderabad, Qabolani Farm Tando Qasir Hyderabad, Mohammad Anwar Bachani Near Mehran Sugar Mil Tando Allahyar, Rafique Fruit Farm Tando Adam Road Tando Allahyar, Zulfiqar Bachani Farm Tando Adam Tando Allahyar Road, and Mir Sher Mohammad Farm Khesana Mori Hyderabad. The flower buds were opened with a needle to determine the presence of larvae of Dasineura amaramanjarae .

\section{Observations method}

The method of observations was as under. The observations were taken randomly from 12 branches of mango tree (one-meter length) each from the top, middle and base) visually from four directions i.e. 3 branches from each direction. The total of 12 branches were observed from each replication with 36 
branches from each variety. Both healthy and infested leaves/branch, number of healthy and infested inflorescence was observed to record infestation percentage of leaves and inflorescence. The mean number of galls/leaf infestation percentage and inflorescence infestation percentage were also recorded.

\section{Biology of midges associated with mango} The Gall midges (Dasineura amaramanjarae ) are very minute. Fragile fly, conducting research wok on biological parameters is very difficult because of their peculiar behaviour. The leaf gall midge completed all its development from egg to adult within the galls while the inflorescences midges larvae fell (after completing development) on the ground for pupation, therefore, for the biology of Dasineura amaramanjarae the following techniques were used for the appropriate result of biological parameters.

\section{Biology of gall midges (Dasineura amaramanjarae )}

In this trial, the data of biological parameters of Dasineura amaramanjarae were recorded on a daily basis. The methodology is given as under: For conducting an experiment on the biology of Dasineura amaramanjarae, five infested twigs of $(15.0 \mathrm{~cm})$ were observed visually from garden of different varieties. The samples were taken randomly from different sides (i.e., east, north, west and south of mango tree) and from different strata (i.e., top, middle and lower of mango trees) of each variety and brought in the laboratory. To keep the collected twigs, live/fresh, the proximal end of each twig was kept in small jars separately by passing it through the small holes in the lids of the jar $(7.5 \mathrm{~cm})$ so as the end remain dipped in the water present in the jars. The jars were then placed in a large cage $(60 \times 60 \times 60 \mathrm{~cm})$ in the laboratory at room temperature of $(25 \pm 20 \mathrm{C})$. Meanwhile, pots (3 in number) of the new and fresh mango seedlings $(22.5 \mathrm{~cm})$ were placed in another cage of the same size. The newly emerged adult of Dasineura amaramanjarae (two males and one female) from the infested twigs were collected by aspirator and released them in the cages having seedling for about 10 - 15 days to record fecundity of the Dasineura amaramanjarae .

The seedlings kept in the cage were examined twice a day for any egg lying on the leaves. Since the egg marks i.e. pinkish-red spots observed sufficient in number on the leaves of the seedling they were replaced with new ones in the cage for further culture needed for the experimentation. The leaves of seedling were examined under a microscope to count the number of egg onto them. Thereafter the seedlings were shifted in the field and covered with muslin cloth. The observations were carried out on daily basis. Five galls from these seedlings were made open daily to examine larval growth under a microscope. The opened galls after examination were marked with a ball-point pen and discarded. In this way, five galls of the same cohort were opened, examined and discarded daily to record time span of each life stage. To record adult emergence and sex ratio the cohort was developed separately with the same procedure; however, none of the galls was opened/ discarded till adult emergence and the pots were kept in a tray containing water to count adult that died after their longevity became over. The experiments of biological parameters were kept to continue for four generations from March to October.

\section{Biology of inflorescence Dasineura amaramanjarae}

In this trial, the data of biology of the inflorescence of Dasineura amaramanjarae were taken on a daily basis for 5 months from February to June. The details of the methodology are as under: The 10 infested inflorescences of $\sim 20 \mathrm{~cm}$ were brought in the laboratory; the proximal end was dipped in water present in small jars $(7.5 \mathrm{~cm} \times 3 \mathrm{dia})$ through the hole in their lids, which then placed in big jars $(40 \times 15 \mathrm{~cm})$. The fallen larvae were taken and placed in a small jar 
containing sterilized soil for pupation. After emergence of adults, one pair (male and female) were released onto newly brought inflorescence in small jars. Before releasing the adults, onto inflorescence, the inflorescence was thoroughly examined for any egg-laying prior in the field. In this way, 3 jars were used (one jar was considered on replication). The jars were covered with muslin cloth for proper ventilation. The moist blotting papers were kept in the bottom of jars to collect and count the fallen larvae, which completed their larval life, and were to transform themselves into pupae. The fallen larvae immediately transferred into small jar containing sterilized soil for pupation. Through this procedure, the data on egglaying, larval period, pupal duration, emergence of adult, adult longevity and sexratios were recorded on a daily bases.

\section{Statistical analysis}

The raw data of all the sampled sites from the mango field orchards of the two consecutive years were transferred in an electronic format in a spreadsheet layout (Microsoft excel, 2016). The data was finally analyzed to calculate important value indices from all the sampling sites. The data thus collected were subjected to statistical analysis using analysis of variances, and randomized complete block design (RCBD), by using software STATISTICS-8.1 with three replications. The difference among the treatments means was compared by LSD (Least Significance Difference) test.

\section{Results and discussion}

Studies carried out on the biology of inflorescence Dasineura amaramanjarae which included the time of adult emergence, number of eggs, hatching period, larval period first instar, $2^{\text {nd }}$ instar, $3^{\text {rd }}$ instar, $4^{\text {th }}$ instar, pupal period, (Adult emergence period), sex ratio, mortality age, survival percentage and total life cycle period. The Dasineura amaramanjarae was first time recorded from Sindh, Pakistan. It was found in all the areas surveyed in Sindh including commercial and non-commercial orchards mentioned above. The specimens were identified by the taxonomist. We examined hundreds of flower buds with a special magnifying glass and found more than 50 to $70 \%$ of total flowers infested with Dasineura amaramanjarae nourishing inside the buds, different numbers of the larvae feeding per flower were observed. They became red pinkish at final stage and pupated in the soil within 1-2 days and red-coloured adults emerged in 3-7 days which survived for 3-4 days. Females were larger, as compared to adult Males.

\section{Number of eggs / female}

After ovipositional, the egg hardens and may change color. Other color changes, especially darkening, are visible before hatch. Fig. 1 showed that there was a highly significant difference between months.

The data further showed that the maximum number of eggs laid/female was recorded in the month of April followed by the month of March and the minimum number of an egg laid/female was recorded in the month of February.

\section{Hatching period}

In the biology of Dasineura amaramanjarae, there was a highly significant difference between months. The data in (Fig. 2) showed that the maximum period of hatching was found in the month January and minimum period of hatching was found in the month of April. 


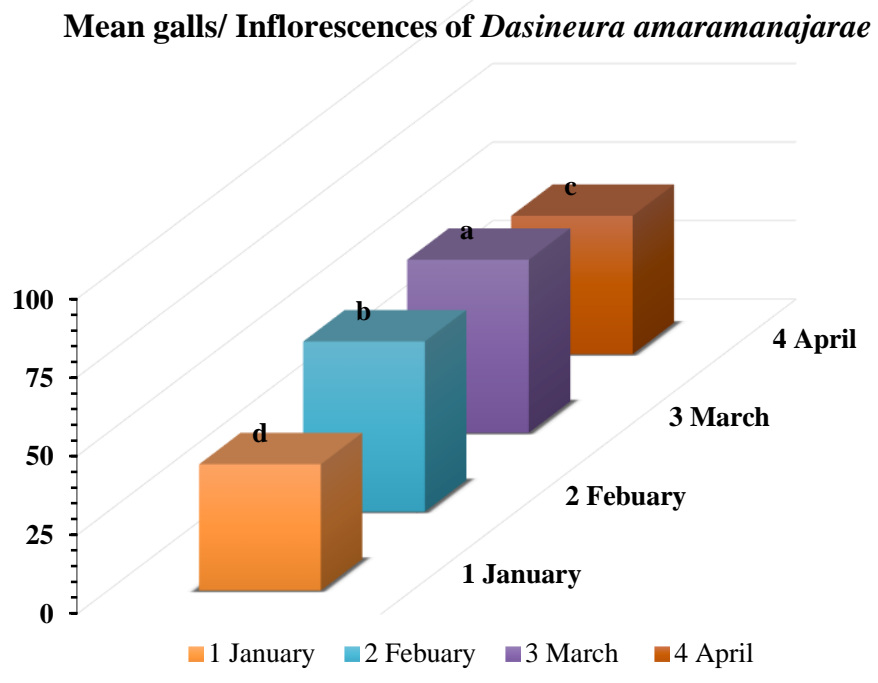

Figure 1. The Mean galls/ Inflorescences of Dasineura amaramanjarae

\section{$1^{\text {st }}$ Instar larvae}

The major role of larvae in the life cycle is to feed and grow. Consequently, their structural and temporal patterns of development are related largely to the need to survive in particular environments (generally chosen by ovipositing females) and to acquire and use the food resources there. In many species, first instars differ from later instars, but in this case, the data given in (Fig. 1) showed that there was a highly significant difference between months. The maximum period of $1^{\text {st }}$ instar larvae was found in the month January and minimum period of $1^{\text {st }}$ instar larvae was found in the month of April.

\section{$2^{\text {nd }}$ Instar larvae}

The data presented in (Fig. 1) showed that there was a highly significant difference between the months. The maximum period of $2^{\text {nd }}$ instar larvae was found in the month of January and February while the minimum period of $2^{\text {nd }}$ instar larvae was found in the month of April.

\section{$3^{\text {rd }}$ Instar larvae}

The data (Fig. 1) showed that there was a highly significant difference between months. The maximum period of $3^{\text {rd }}$ instar larvae was found in the month of January and February while the minimum period was found in the month of April.

\section{$4^{\text {th }}$ Instar larvae}

Once feeding ends, the final-instar larva enters the pre-pupal stage. The data (Fig. 1, and 2), showed that there was a highly significant difference between months. The maximum period of $4^{\text {th }}$ instar larvae was found in the month April and minimum period of $4^{\text {th }}$ instar larvae was found in the month of March.

\section{Pupa period (adult emergence period)}

The data (Table 1, Fig. 2) showed that there was a highly significant difference between months. The maximum period of pupa was recorded in the month April and minimum period of pupa was recorded in the month of March respectively. 
Table 1. Mean period (days) of egg hatching, larval instars of Dasineura amaramanjarae

\begin{tabular}{|c|c|c|c|c|c|c|}
\hline Month & Mean galls/ Inflorescences & Hatching & 1st, instar & 2nd instar & 3rd instar & 4th instar \\
\hline Jan & 40 & $1.80 \pm 0.26$ & $2.20 \pm 0.34$ & $2.10 \pm 0.32$ & $2.40 \pm 0.38$ & $2.16 \pm 0.33$ \\
\hline Feb & 54 & $1.60 \pm 0.20$ & $1.21 \pm 0.08$ & $2.00 \pm 0.30$ & $2.20 \pm 0.34$ & $2.12 \pm 0.33$ \\
\hline Mar & 55 & $1.10 \pm 0.04$ & $1.22 \pm 0.09$ & $1.88 \pm 0.27$ & $2.10 \pm 0.32$ & $1.92 \pm 0.28$ \\
\hline April & 44 & $1.06 \pm 0.03$ & $1.10 \pm 0.04$ & $1.62 \pm 0.21$ & $1.82 \pm 0.26$ & $255.98 \pm 2.41$ \\
\hline
\end{tabular}

Mean \pm SE period (days) of egg hatching, 1st,2nd, 3rd, 4th instars of Dasineura amaramanjarae,

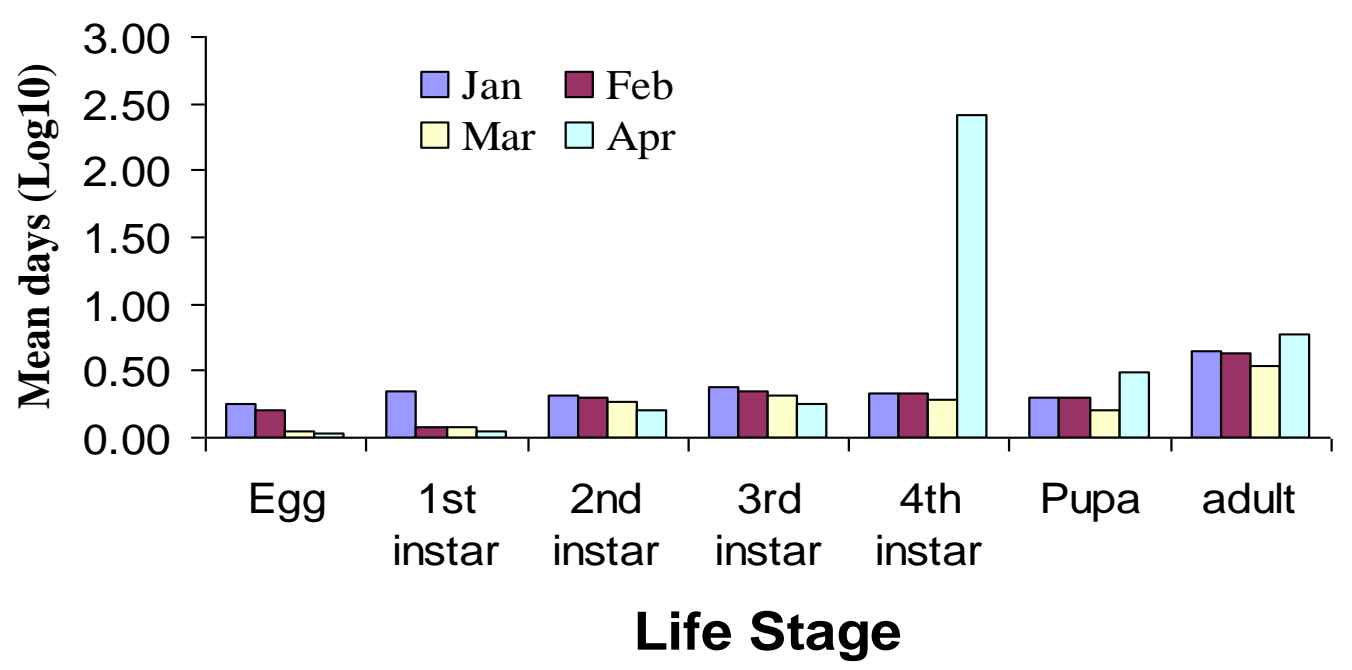

Figure 2. The Biology of mango inflorescence Dasineura amaramanjarae during different months of 2008

\section{Adult longevity}

The results showed that there was a significant difference between months (Table 2, Fig. 1). The maximum adult longevity was found in the month of April and the minimum period of adult longevity was found in the month of March. There was a positive correlation between egg hatching and in total life period. Total life cycle period

The data (Table 2, Fig. 1) showed that there was a highly significant difference between time periods in different months. The maximum life cycle period was found in the month of April and the minimum life cycle period was recorded in the month of March. It means that there was an impact of temperature on the duration life cycle. This showed that when the temperature decreased the life cycle will be decreased when temperature increased the duration of the life cycle will be increased. The biology of inflorescence gall midges indicated that egg hatched in $1.06 \pm 0.03-$ $1.80 \pm 0.26$ days. The first instar lasted for $1.10 \pm 0.04-2.20 \pm 0.34$ days, the second instar $1.62 \pm 0.21-2.10 \pm 0.32$ days, the third instar $1.82 \pm 0.26-2.40 \pm 0.38$ days and fourth instar lasted for $1.92 \pm 0.28-255.98 \pm 2.41$ days. The pupal period (adult emergence period) lasted for 1.60 $\pm 0.20-3.12 \pm 0.49$ days and adult longevity period lasted for $3.46 \pm 0.54$ $6.00 \pm 0.78$ days. The total life cycle period completed in $13.28 \pm 2.48-270.7 \pm 15.28$ days respectively. The similar results were reported previously by Srivastava, (1997) who 
investigated the biology of Dasineura amaramanjarae and reported that the female laid 40.00-50.00 eggs and their hatching period ranged 30.00-34.00 hours. The first instar larvae lasted for 40.00-45.00 hours, the second instar for 48.00-50.00 hours, third instar for 48.00-50.00 hours, fourth instar larvae last for about 50.00-60.00 hours and the pupation period varies from 4.00-6.00 days. The life cycle completed in 15.00-16.00 days. The mortality and survival percentage age were observed during the biology of midges. The maximum means of mortality age percentage of adult were observed in the month of April and minimum (18.58) in the month of March while the maximum means of survival percentage age were observed (81.42) in the month of March and the minimum means of survival percentage age were observed (76.52) in the month of April respectively. The sex ratio of male and female showed that the maximum ratio of male was observed (46.83) in the month of February and the minimum ratio of male was observed (22.72) in the month of March whereas the maximum ratio of female was observed (77.27) in the month of March and minimum ratio of female was observed (53.14) in the month of February. The results showed that there was a significant difference among the all observed factors. In conclusions, midge was found in all surveyed location Sindh. Females lay eggs on flower buds and larvae feed inside the buds and pupate in the soil in
April [20, 21]. Biology showed that activity of Dasineura amaramanjarae mostly started in February and reached a peak in March. The Dasineura amaramanjarae followed an aggregated pattern of distribution numbers of the larvae were significantly higher on the southern side of the trees than all other horizontal sides and significantly less at $6 \mathrm{~m}$ height of tree canopy [3]. The adults of Dasineura amaramanjarae emerged in February. Larvae fed inside the buds at the base of stamen and carpel. Numbers of the larvae feeding per flower in different ranges. They dropped on to the soil under the mango tree for pupation. Dasineura amaramanjarae was noted from February to April when flowers were available and were not found from May to January on of mango trees. During the inactive period, they were not recorded on malformed inflorescences on mango trees and flowers of other nearby areas of experimental orchard. Their pupae were found in the soil under a mango tree canopy. In a study, larvae of Dasineura amaramanjarae damaged mango trees by feeding on buds and flowers [22]. Numbers of larvae were observed in severe infestation. Although the emergence of adults varied in different years yet was synchronized with flowering on mango [23]. Larvae of Dasineura amaramanjarae overwintered in soil under mango trees $[13,15,24,25]$. These components are essential for developing an IPM program.

Table 2. Mean period (days) of Pupa, adult longevity, total life period, and the sex ratio of Dasineura amaramanjarae

\begin{tabular}{|c|c|c|c|c|c|}
\hline \multirow{2}{*}{ Month } & \multirow{2}{*}{ Mean galls/ Inflorescences } & \multirow{2}{*}{ Pupa } & \multirow{2}{*}{ Adult longevity } & Total life & Ratio \\
\cline { 5 - 6 } & & & & Period & Female : Male \\
\hline Jan & 40 & $2.00 \pm 0.30$ & $4.40 \pm 0.64$ & $17.06 \pm 3.52$ & $01: 01.6$ \\
\hline Feb & 54 & $2.00 \pm 0.30$ & $4.34 \pm 0.64$ & $15.47 \pm 2.42$ & $01: 02.4$ \\
\hline Mar & 55 & $1.60 \pm 0.20$ & $3.46 \pm 0.54$ & $13.28 \pm 2.48$ & $01: 01.3$ \\
\hline April & 44 & $3.12 \pm 0.49$ & $6.00 \pm 0.78$ & $270.70 \pm 15.28$ & $01: 01.4$ \\
\hline
\end{tabular}

Mean \pm SE period (days) of Pupa, adult longevity, total life period, and the ratio of Dasineura amaramanjarae 


\section{Conclusion}

In the light of this study as Dasineura amaramanjarae was newly found in Sindh region. The Dasineura amaramanjarae go through four distinct stages during their life cycle. Knowing the different stages of the gall midges life will help you prevent Dasineura amaramanjarae, and also help you select the right time, and practices for your needs, if you decide to use them. To understand the biology of Dasineura amaramanjarae is very essential for developing an IPM program. Our findings will deliver useful information to pest managers of mango orchards.

\section{Authors' contributions}

Conceived and designed the experiments: MQ Memon, Performed the experiments: MQ Memon \& AG Lanjar, Analyzed the data: AG Lanjar, Contributed materials/ analysis/ tools: MK Lohar, MA Rustamani, AS Buriro \& M Qadir, Wrote the paper: MQ Memon \& SA, Nahiyoon.

\section{Acknowledgement}

The authors are highly indebted to the Faculty of Crop Protection, Sindh Agriculture University Tandojam. Laboratory equipment's, good environment and guidance during present research work. Besides this, we are also very thankful to the anonymous reviewers for their valuable suggestions which enabled us to present the refined version of this work.

\section{References}

1. Asif I, Faisal FS, Munawar KR, Chrys AN, Gul BP \& Nazim LH (2011). Trend of mango sudden death syndrome (MSDS) in relation to fungal microflora and nematodes fauna in Punjab, Pakistan. Pak J Nematol 29(1): 45-51.

2. Deeprndra YS, \& Sing SP (2017). Mango: Histroy origin, \& distribution. $J$ of Pharmacog \& Phytochem 6(6): 1257-1262.

3. Hafiz MR, Riaz M, and Razaq M (2013). Phenology, Population Dynamics and Within Tree Distribution of Dasineura amaramanjarae

Grover,

1965
(Diptera:Cecidomyiidae) in Punjab, Pakistan. Pak J Zool 45(6): 1563-1572.

4. Peña JE, Mohyuddin AI \& Wysoki M (1997). The current mango pest's management in the tropics and subtropics. Acta Horticul 455(1): 812-820.

5. Qureshi SA \& Mohyuddin S (1982). Insect pests of mango recorded from Pakistan Proceedings Entomol Soc Karachi 11(12): 19-22.

6. Tandon PL, Verghese A, \& Prasada GS (1989). Spatial distribution, sampling Plan \& appropriate transformation of mango hopper.Gionale Italino di Entomol 4(1): 235-242.

7. Abbas SA (1985). Studies on the mango inflorecence midge, Erosomyia indica Grover. Acta Horticul 231(1): 593-596.

8. Venkata RP, Gundappa BR \& Chakravarthy AK (2018). Pests of Mango. Pests and their managemen.11(3): 415440.

9. Mohyudin AI \& Mahmood RA (1993). Integrated control of mango pests in Pakistan. Acta Horticul 341(5): 467-483.

10. Sathe TV, Desai AS, Bhoje PM \& Jadhav DK (2014). Pests of Mango Mangifera Indica Linn. at Storage, and Their Control. Indian J of Appl Res 4(7): 1-4.

11. Mohyuddin AI, \& Mahmood RI (1993). Integrated control of mango pests. Bulletin Directorate Publications, PARC Islamabad. ISHS Acta Horticul 341(11): 341-351.

12. Grover PI (1966). The biology of Erosomyia indica Grover, The most serious pest of mango in India. Cecidologia indica 1(2): 1-23.

13. Prasad SE (1966a). Gall-midges of economic importance V. Biology of Erosomyia indica Grover, the most serious pest of mango in India. Cecidologia indica 1(2): 1-23.

14. Grover P (1985). Protection of mango crop against newly discovered midge pests. Cecidol Int 1(6): 35-40. 
15. Grover P (1986). Population fluctuation of Erosomyia indica and Dasineura amaramanjarae and extent of damage. Cecidol Int 3(7): 1-57.

16. Grover P (1965). Studies on Indian gall midges (Diptera: Cecidomyiidae)-X11. The mango blossom midge, Dasineura amaramanjarae, n. sp.Ann. Ento Soc Amer 58(2): 202-206.

17. Prasad SN \& Grover PI (1976). Pest status of Erosomyia indica - a midge pest of mango. Cecidologia Indica 11(3): 25-56.

18. Prasad SN (1966). The relation of mango blossom midge

(Dasineura amaramanjarae) to the yield of mango. Cecidol Int 3(1): 171-184.

19. Sharma SA, Kooner RA \& Arrora RA (2017). Insect Pests and crop Losses. Breeding Insect Resistant Crops for Sustainable Agri 9(1): 45-66.

20. Askari MA \& Bagheri AI (2005). Biology and comparative morphology of two cecid flies, Procontrinia mattiana \& Erosomyia Mangifera (Dip.: Cecidomyiidae), in
Hormozgan province. J Entomol Soc Iran 25(1): 27-42.

21. Anwar MR, Zahoor MH, Saeed AI \& Fakharuddin MR (2006). Vegetative and Reproductive Physiology of April Flush in Mango (Mangifera indica L.) cv. Dusehri. Int J Agri Biol 8(4): 452-454.

22. Saif UM, Muhammad SA, \& Lodhi TE (2007).Communication gap regarding plant protection, harvesting and post-harvest technologies among the mango grower. Pak J Agri Sci 44(1): 654-659.

23. Pena JI, Mohyuddin AR \& Wysoki MK (1998). A review of the pest management situation in mango agroecosystems. Phytoparasitica 7(26): 1-20.

24. Metcalf RL \& Luckmann WH (1994). Introduction to insect pest management, 3rd edn. John Wiley \& Sons, New York 1/34(7): $1-57$.

25. Zadocks JE (1993). Crop protection: why and how In: Crop protection and sustainable agriculture. (eds. D.1. Chadwick and I. Marsh), John Wiley and Sons, Chichester 9/4(5). 48-60. 